\title{
Homofobia Internalizada e Religiosidade entre Casais Homoafetivos
}

\author{
Elder Cerqueira-Santos ${ }^{1}$ \\ César Augusto de Sá G. Carvalho \\ Lucas Menezes Nunes \\ Aline Pompeu Silveira \\ Universidade Federal de Sergipe, São Cristóvão, SE, Brasil
}

\begin{abstract}
Resumo
O objetivo deste estudo foi investigar a relação entre a religiosidade e o constructo "homofobia internalizada". Parte-se da hipótese de que a religiosidade é uma das variáveis de forte argumento moral negativo sobre as minorias sexuais, sendo então parte da construção pessoal que rejeita a própria homossexualidade. Participaram do estudo 94 pessoas, 49 homens e 45 mulheres, vivendo em um relacionamento estável com parceiro do mesmo sexo. O instrumento investigou quatro dimensões: dados sociodemográficos (idade, sexo, renda, escolaridade, religião, tempo de relacionamento, tempo que mora junto, ocupação e filhos), religiosidade, satisfação conjugal e homofobia internalizada. Os dados foram coletados de forma presencial com instrumento auto-aplicável e analisados a partir de teste $t$, correlação de Pearson e regressão linear com a homofobia internalizada. Os resultados apontaram maiores níveis de homofobia internalizada entre os grupos de maior religiosidade, confirmando a hipótese inicial. O modelo de regressão linear final mostrou como variáveis associadas à homofobia internalizada: religiosidade, tempo de relacionamento, ter filhos e satisfação conjugal. Os dados alertam para a importância da influência de comportamentos como a religiosidade na vivência da sexualidade. Discute-se que o preconceito contra as minorias sexuais pode ser introjetado por parte dos indivíduos que pertencem ao grupo minoritário, provocando sofrimento.
\end{abstract}

Palavras-chave: Homofobia, religiosidade, preconceito.

\section{Internalized Homophobia and Religiosity among Homosexual Couples}

\begin{abstract}
The goal of this study was to investigate the relationship between religiosity and the "internalized homophobia" construct. The mean hypothesis is that religiosity is one of the strongest negative variables associated with moral arguments about sexual minorities, being part of the personal construction who rejects its own homosexuality. The study included 94 people, 49 men and 45 women living in a stable relationship with a same sex partner. The instrument investigated four dimensions: sociodemographic data (age, sex, income, education, religion, relationship time extension, time living together, occupation and children), religiosity, marital satisfaction and internalized homophobia. Data was collected in

Endereço para correspondência: Universidade Federal de Sergipe, Departamento de Psicologia, Av. Marechal Rondon, s/n, Campus da UFS, Bloco Departamental IV, São Cristóvão, SE, Brasil 49100-000. Fone: 792105 6600. E-mail: eldercerqueira@gmail.com

Financiamentos: Conselho Nacional de Desenvolvimento Científico e Tecnológico (CNPq) e A Fundação de Apoio à Pesquisa e à Inovação Tecnológica do Estado de Sergipe (FAPITEC-SE).
\end{abstract}


person with a self-administered questionnaire and analyzed with $t$ test, Pearson correlation and linear regression with internalized homophobia. The results showed higher levels of internalized homophobia among the most religious groups, confirming the initial hypothesis. The final linear regression model showed how variables such as the effect of religiosity, relationship time, the fact of having children and marital satisfaction associate with internalized homophobia. The data indicated the importance of religious behaviors in influencing the experience of sexuality. It is argued that prejudice against sexual minorities can be introjected by individuals belonging to the minority group, which causes suffering.

Keywords: Homophobia, religiosity, prejudice.

\section{La Homofobia Internalizada y Religiosidad entre las Parejas Homosexuales}

\section{Resumen}

El objetivo de este estudio fue investigar la relación entre religisidade y el constructo "homofobia internalizada". Se inicia con la hipótesis de que la religiosidad es uno de los fuertes variables de argumentos morales negativos sobre la minoría sexual, por lo que ser parte de la costrucción personal que rechaza su propia homosexualidad. Participó en la población de estudio 94 que se declararon homosexuales que viven en una relación estable. Se utilizaron, una escala de homofobia internalizada, escala de religiosidad, los datos acerca de la sexualidad y la escala de satisfacción marital. Los datos fueron recogidos en persona con el instrumento autoadministrado. Los datos mostraron mayores niveles de homofobia internalizada entre los grupos más religiosos, lo que confirma la hipótesis inicial. Un modelo final para las variables asociadas con la homofobia internalizada destacó la religiosidad, el tiempo de relacion, el hecho de tener hijos y la satisfacción marital. Los datos llaman la atención sobre la importancia de la comprensión de cómo la religiosidad influencia en la experiencia de la sexualidad. Se argumenta que los prejuicios contra las minorías sexuales puede ser internalizado por los mismos individuos que forman parte del grupo minoritario y causa sufrimiento.

Palabras clave: Homofobia, religiosidad, preconcepto.

Criado em 1971 pelo psicólogo George Weinberg, o termo Homofobia substantifica o descrédito, opressão e violência direcionada aos indivíduos homossexuais ou àqueles presumidos como tal (Borrillo, 2000; Eribon \& Haboury, 2003; Teixeira-Filho \& Marretto, 2008). A homofobia pode partir de pessoas heterossexuais direcionada a sujeitos não heterossexuais, como também pode manifestar-se a partir do próprio indivíduo não heterossexual em direção a si e a outras pessoas pertencentes ao(s) mesmo(s) grupo(s), bem como a tudo o que fizer alusão à não-heterossexualidade (Eribon, 1999). Quando este fenômeno acontece, recebe a alcunha de homofobia internalizada, que se conceitua como uma atitude negativa por parte dos indivíduos não heterossexuais acerca da sua orientação sexual (Hernández, 2013).
A Homofobia internalizada pode evidenciar um mecanismo psicológico de blindagem da própria identidade, mediante a qual se marca um limite que separa simbolicamente o indivíduo do grupo estigmatizado (Rodrigues, 2010). Tais indivíduos, como forma de proteção, passam a aceitar o sistema de crenças que condena a orientação sexual não heterossexual; trata-se de uma solução parcial para resolver o conflito entre a identidade e o sistema de crenças estabelecidos (Hernández, 2013). Portanto, o termo homofobia internalizada (ou homofobia implícita) está relacionado a atitudes que são de caráter subjetivo como, por exemplo: "Não gosto de pensar na minha homossexualidade" e "Gostaria de ser mais heterossexual" (Pereira \& Leal, 2005).

Em estudos recentes (Barrientos \& Cárdenas, 2013; Freires, 2015; Herek, 2000, 2004; 
Herek \& McLemore, 2013), há uma crescente evolução na discussão acerca do uso do termo homofobia como representativamente limitado à agressão física e verbal contra indivíduos não heterossexuais, estando assim muito mais cornubada à homofobia explícita - caracterizada por comportamentos de interação social - quando, na verdade, o escopo da homofobia transcende os aspectos físicos e verbais e engloba formas mais sutis de violência como não apoiar políticas públicas que visam a ampliação ou conquista dos direitos dessa população. Além disso, o termo é comumente usado para substantificar também a violência sofrida por indivíduos transexuais, travestis ou que não se posicionam em nenhum dos pólos da identidade de gênero. Mediante este cenário, surgem termos como "preconceito sexual" e "discriminação heterossexista" para suprir essa demanda (Freires, 2015). Somado a isto, alguns autores tem discutido a possibilidade de mudança do termo homofobia internalizada para homonegatividade (Costa \& Nardi, 2015; Freires, 2015). No entanto, neste estudo optamos por utilizar o primeiro, pois mesmo cientes da discussão que as diferentes terminologias apresentam, o termo homofobia (e homofobia internalizada), além de popularizado, é consagrado pela literatura e utilizado em diversos instrumentos e escalas de avaliação.

Atualmente as Políticas Públicas voltadas aos direitos LGBT (Lésbicas, Gay, Bissexuais, Transsexuais e Travestis) no Brasil obtiveram considerável avanço. Entretanto, a frase que parece marcar as discussões em pesquisas envolvendo este tema é "nunca se teve tanto e o que há é praticamente nada", isso porque entende-se que há dimensões do preconceito e da discriminação heterossexista culturalmente arraigados que são constantemente reproduzidos no cotidiano (Mello, Avelar, \& Brito, 2014). Logo, todos aqueles que não se adequam aos papéis sociais vigentes de homem/mulher, tornam-se marginalizados, estranhos, diferentes e, muitas vezes, vítimas de preconceito (Freires, 2015). Um fator que pode contribuir com esta realidade é a vigência do pensamento conservador de matriz religiosa que materializa o pressuposto de uma heteronormatividade sexual (Natividade, 2006) que têm interferido decisivamente - e até mesmo controlado - os debates acerca dos direitos das minorias sexuais no Brasil e no mundo, comprometendo assim o princípio de laicidade constitucional do Estado (Mello et al., 2014).

Religião, palavra que vem do latim religio, é formada pelo prefixo re (outra vez, de novo) e o verbo ligare (ligar, unir, vincular) e representa uma busca de vinculação da pessoa ao divino (Cerqueira-Santos, Koller, \& Pereira, 2004). Apesar da atual hegemonia científica e difusão de aparatos tecnológicos e de informação, a religião ainda continua sendo bastante utilizada para responder e dirigir questões que se apresentam na vida das pessoas, pois se configura como uma instância que codifica e impõe aos seus adeptos códigos morais, atuando como ferramenta de controle social (Durkheim, 1915/2003), já que se transforma em um forte laço de regulação que impulsiona seus adeptos a manterem determinado comportamento, difundido como correto (Meneses \& Cerqueira-Santos, 2013). Cerqueira-Santos et al. (2004) fazem uma importante distinção entre os termos religiosidade e espiritualidade, destacando que enquanto a espiritualidade diz respeito ao domínio individual e subjetivo sobre a crença, a religiosidade está num domínio social e institucionalizado. Entende-se assim neste estudo a religiosidade como prática institucionalizada e socialmente compartilhada que envolve crenças em qualquer mitologia.

Estudos de Costa, Peroni, Camargo, Pasley e Nardi (2015) e Natividade e de Oliveira (2009) encontraram relações entre religiosidade, sexualidade e nível de preconceito. Costa e colaboradores (2015) mostraram que religiosidade e conservadorismo ético apresentam associação no que diz respeito ao preconceito contra diversidade sexual. Os autores pontuam que tal fato não parte da religião por si só, mas sim de uma posição conservadora generalizada no que diz respeito aos assuntos de moralidade pessoal. Além disso, Cerqueira-Santos, Koller e Wilcox (2014) e Coutinho e Miranda-Ribeiro (2014) afirmam que a religião tem mostrado ser um fator importante na maneira como jovens vivem sua sexualidade, principalmente ao diminuir a incidência de comportamentos de risco e re- 
tardar a idade de iniciação sexual. A literatura (Pereira, Torres, Pereira, \& Falcão, 2011; Sung, 2014; Verona \& Regnerus, 2014) aponta que a religiosidade, pautada em ideais conservadores, possui relação estreita com a homofobia explícita (Natividade, 2006; Silva, Santos, Licciardi, \& Paiva, 2008). No entanto, em pesquisa nas principais bases de dados de periódicos científicos do Brasil (Scientific Electronic Library Online [SCIELO] e portal de Periódicos Eletrônicos de Psicologia [PEPSIC]), não foi encontrado nenhum artigo que relacionasse homofobia internalizada e religiosidade. Deste modo, o objetivo geral deste estudo é investigar a relação entre a homofobia internalizada e o nível de religiosidade do indivíduo homossexual. A principal hipótese baseada na literatura é que maiores níveis de religiosidade estão associados a maiores níveis de homofobia internalizada.

\section{Método}

\section{Participantes}

Este estudo é parte integrante de um projeto multicêntrico nacional que acompanha casais homoafetivos e investiga diversos fatores associados. Os critérios de inclusão considerados foram: (a) estar vivenciando uma relação conjugal (ou união estável) com parceiro(a) do mesmo sexo há, pelo menos, um ano e/ou (b) coabitar com o(a) cônjuge do mesmo sexo há, pelo menos, seis meses; (c) ter idade mínima de 18 anos. Os participantes podiam ou não ter filhos (advindos de relacionamento anterior ou do atual), como também não era obrigatória a participação dos dois indivíduos que formavam o casal.

Como pode-se verificar na Tabela 1 , a amostra foi composta majoritariamente de homens, representando $52,7 \%$ dos respondentes, o nível de escolaridade dominante foi a Graduação $(64,9 \%)$, seguido pela pós-graduação $(18,1 \%)$ e Ensino Médio Completo (12,8\%). Apresentaram atividade remunerada $63,8 \%$ dos indivíduos e $61,7 \%$ declararam seguir alguma religião, sendo a católica a denominação predominante $(36,2 \%)$, seguida da espírita (16\%), evangélica $(3,2 \%)$ e $6,4 \%$ não responderam qual religião seguem. A média de idade da amostra foi de 28,32 anos, o tempo de relacionamento médio foi de 49,57 meses e, entre os participantes que moram juntos, a média de residência conjunta foi de 42,64 meses. Doze por cento dos sujeitos participantes têm filho(s) e no que diz respeito à renda individual, a média foi de R 2.094 .

\section{Instrumentos}

Questionário Sociodemográfico: este questionário buscou caracterizar sociodemograficamente os participantes conforme os objetivos do estudo: idade, sexo, renda, escolaridade, religião, tempo de relacionamento, tempo que mora junto, ocupação e filhos.

Escala De Religiosidade/Espiritualidade (Cerqueira-Santos et al., 2008): Esta escala mede a religiosidade/espiritualidade através dos seguintes aspectos destacados na literatura: afiliações religiosas, prática e crença. O instrumento é composto por nove itens e deve ser respondido numa Escala Likert, com valores variando de 1 - Nunca a 5 - Sempre. Exemplos de itens da escala: "a religião/espiritualidade tem sido importante na minha vida", "costumo frequentar encontros, cultos ou rituais religiosos", "peço ajuda a Deus para resolver meus problemas", dentre outros. A análise fatorial destes itens confirmou o uso de um único fator $(\mathrm{KMO}=0,86)$, com uma variância explicada de $57 \%$. A versão original da escala, composta de sete itens, apresentou um alpha Cronbach de 0,87. O alpha de Cronbach para a amostra deste estudo foi de 0,83 , considerando os itens em forma unifatorial. A escala permite aplicação para indivíduos com ou sem religião, pois explora aspectos da espiritualidade e considera escores mínimos para grupos sem crença alguma.

Escala de Satisfação Conjugal - GRIMS (Falcke, 2003): esta escala é constituída por um questionário de 28 itens e o/a entrevistado/a teve de pontuar em uma escala Likert de 4 pontos (discordo fortemente, discordo, concordo e concordo fortemente) o quanto concordou/discordou da afirmação. Esta escala mede a qualidade do relacionamento conjugal através das seguintes dimensões: satisfação, comunicação, interesses compartilhados, confiança e respeito. 
Tabela 1

Dados Sociodemográficos $(\mathrm{N}=98)$

\begin{tabular}{|c|c|c|c|c|c|}
\hline \multirow{2}{*}{\multicolumn{2}{|c|}{ Variáveis }} & \multicolumn{4}{|c|}{ Valores } \\
\hline & & Min & Max & Média & $D P$ \\
\hline \multicolumn{2}{|l|}{ Idade (em anos) } & 19 & 57 & 28,32 & 7,71 \\
\hline \multicolumn{2}{|c|}{ Tempo de Relacionamento (em meses) } & 12 & 213 & 49,57 & 36,43 \\
\hline \multicolumn{2}{|c|}{ Tempo que mora junto (em meses) } & 3 & 164 & 42,64 & 35,75 \\
\hline \multirow{2}{*}{\multicolumn{2}{|c|}{ Renda Individual (em R\$) }} & 0 & 11.000 & 2.094 & 1954 \\
\hline & & \multicolumn{2}{|c|}{ Porcentagem } & \multicolumn{2}{|c|}{ Frequência } \\
\hline \multirow{4}{*}{ Sexo } & Homens & \multicolumn{2}{|c|}{52,7} & \multicolumn{2}{|c|}{49} \\
\hline & Mulheres & \multicolumn{2}{|c|}{47,3} & \multicolumn{2}{|c|}{45} \\
\hline & Graduação & \multicolumn{2}{|c|}{64,9} & \multicolumn{2}{|c|}{61} \\
\hline & Pós-graduação & \multicolumn{2}{|c|}{18,1} & \multicolumn{2}{|c|}{17} \\
\hline \multirow{4}{*}{ Escolaridade } & Ensino Médico Completo & \multicolumn{2}{|c|}{12,8} & \multicolumn{2}{|c|}{12} \\
\hline & Ensino Fundamental Completo & \multicolumn{2}{|c|}{2,1} & \multicolumn{2}{|c|}{2} \\
\hline & Ensino Médio Incompleto & \multicolumn{2}{|c|}{1,1} & \multicolumn{2}{|c|}{1} \\
\hline & Não respondeu & \multicolumn{2}{|c|}{1,1} & \multicolumn{2}{|c|}{1} \\
\hline \multicolumn{2}{|l|}{ Possui religião } & \multicolumn{2}{|c|}{61,7} & \multicolumn{2}{|c|}{58} \\
\hline \multirow{5}{*}{ Religião Professada } & Não tem religião & \multicolumn{2}{|c|}{38,3} & \multicolumn{2}{|c|}{36} \\
\hline & Católica & \multicolumn{2}{|c|}{36,2} & \multicolumn{2}{|c|}{34} \\
\hline & Espírita & & & & \\
\hline & Não respondeu & & & & \\
\hline & Evangélica & & & & \\
\hline Trabalha & & & & & \\
\hline Mora junto & & & & & \\
\hline Tem filhos & & & & & \\
\hline
\end{tabular}

$\mathrm{Na}$ pontuação da escala, verifica-se que quanto maiores os escores obtidos, mais severos são os problemas no relacionamento conjugal. O questionário inicia-se mediante a seguinte reflexão: pensando no seu relacionamento atual com seu marido/esposa/companheiro(a)/namorado(a), responda as próximas questões: 1) Meu companheiro geralmente sabe das minhas necessidades e é sensível a elas; 2) Eu realmente aprecio o senso de humor do meu companheiro; 3) Meu companheiro parece não querer mais me ouvir; dentre outras. Foi utilizada versão unifatorial com alpha de Cronbach de 0,89.
Escala de Homofobia Internalizada (Pereira \& Leal, 2005): esta escala avalia os níveis de internalização do preconceito contra homossexuais. Consiste num questionário de 25 itens distribuídos em duas dimensões - percepção interna do estigma e percepção externa do estigma. Todos os itens são redigidos na afirmativa e medidos numa escala de Likert de 5 pontos, desde 1 - discordo totalmente a 5 - concordo totalmente. Seguem alguns itens da escala: 1) Homens gays obviamente efeminados fazem-me sentir desconfortável (dimensão 1); 2) Prefiro ter parceiros/as sexuais anônimos (dimensão 1); 
3) A vida seria mais fácil se eu fosse heterossexual (dimensão 2), dentre outros. O Alpha de Cronbach para o escore geral foi de 0,74 (sendo 0,816 para a primeira dimensão e 0,645 para a segunda).

\section{Procedimentos de Coleta de Dados}

Os integrantes do grupo de pesquisa entraram em contato com informantes-chave que se enquadravam nos pré-requisitos do estudo para que fizessem parte da amostra e, em seguida, foi utilizado o método snowball (bola de neve) a partir destas participações iniciais para identificar outros potenciais respondentes. Ao todo participaram do estudo 94 indivíduos.

Aos participantes foram explicados os objetivos da pesquisa, esclarecidas as questões éticas do estudo e solicitada a assinatura do Termo de Consentimento Livre e Esclarecido (TCLE). Somente após o consentimento é que se dava início à coleta de dados. Todos os instrumentos foram autoaplicáveis e o tempo médio de aplicação foi de 30 minutos. Durante a aplicação, o pesquisador esteve disponível para retirar quaisquer dúvidas dos participantes.

\section{Procedimentos de Análise de Dados}

Os dados de cada participante foram digitados no Statistical Package for Social Science - SPSS (versão 21) e submetidos a análises descritivas e inferenciais. Realizou-se o cálculo de estatísticas descritivas (frequência, porcentagem e média) para a amostra total, com foco nas variáveis utilizadas neste estudo: aspectos sociodemográficos, homofobia internalizada e índice de religiosidade. Foram executadas análises bivariadas com o uso do teste $t$ para amostras independentes tendo como variável de comparação a homofobia internalizada. Além disso, também foi realizado teste de correlações de Pearson entre as variáveis do estudo e, por fim, uma análise de regressão linear tendo como variável dependente o escore de homofobia internalizada.

Foram categorizadas as variáveis idade, renda pessoal, tempo de relacionamento e religiosidade. O ponto de corte para divisão em grupos de idade foi de 35 anos. Para renda foi R\$ 1400,00; tempo de relacionamento foi de 2 anos; ambos baseados na mediana dos dados da amostra. Para religiosidade a categorização foi feita dividindo o escore em três partes sendo considerados apenas os extremos (alta ou baixa religiosidade), conforme Cerqueira-Santos et al. (2008).

\section{Procedimentos Éticos}

O projeto desta pesquisa foi submetido e aprovado pelo Comitê de Ética em Pesquisas envolvendo Seres Humanos da Universidade Federal de Sergipe (protocolo número 50367715.0.0000.5546). A pesquisa atende às recomendações bioéticas para pesquisas com seres humanos no que diz respeito à Resolução 466/2012 do Conselho Nacional de Saúde (CNS). Os participantes foram informados sobre os princípios bioéticos, sobre os objetivos e procedimentos do estudo quando convidados para participar voluntariamente da pesquisa e assinaram o TCLE.

\section{Resultados}

A Tabela 2 apresenta uma análise bivariada com o uso do teste $t$ para amostras independentes entre algumas das variáveis do estudo, tendo a homofobia internalizada como a variável de comparação. Foi encontrada diferença significativa somente nas variáveis "tem filho(s)" e "religiosidade". Para o grupo de participantes que relataram ter filhos, a média de homofobia internalizada foi menor $(9,36)$ do que os que relataram não ter filhos $(13,97)$, sendo $t=2,367$ e $P=$ 0,033 . Para a variável "religiosidade", o grupo com escores mais altos de religiosidade apresentaram também escores mais altos de homofobia internalizada $(14,82)$ comparando com 11,79 do grupo menos religioso $(t=2,09$ e $P=0,04)$. Além dos dados estatisticamente significativos, é importante citar que as maiores médias de homofobia internalizada foram percebidas entre homens, maiores de 35 anos, com renda superior a $\mathrm{R} \$ 1400,00$, com menos de dois anos de relacionamento, que não trabalham, não tem filhos, tem religião e apresentam religiosidade alta. 
Tabela 2

Análise Bivariada para Média de Homofobia Internalizada

\begin{tabular}{|c|c|c|c|c|c|}
\hline \multicolumn{2}{|c|}{ Características } & \multicolumn{4}{|c|}{ Homofobia Internalizada } \\
\hline & & Média $(D P)$ & $t$ & $g l$ & $P$ \\
\hline \multirow{2}{*}{ Sexo } & Masculino & $14,08(7,87)$ & \multirow{2}{*}{1,02} & \multirow{2}{*}{89,22} & \multirow{2}{*}{0,309} \\
\hline & Feminino & $12,59(6,12)$ & & & \\
\hline \multirow{2}{*}{ Idade } & Menos de 35 & $13,26(7,15)$ & \multirow{2}{*}{0,029} & \multirow{2}{*}{14,26} & \multirow{2}{*}{0,977} \\
\hline & Mais de 35 & $13,33(7,30)$ & & & \\
\hline \multirow{2}{*}{ Renda pessoal } & Menos de 1400 & $12,97(6,07)$ & \multirow{2}{*}{0,491} & \multirow{2}{*}{91,59} & \multirow{2}{*}{0,625} \\
\hline & Mais de 1400 & $13,71(7,87)$ & & & \\
\hline \multirow{2}{*}{ Tempo de relacionamento } & Menos de 2 anos & $14,07(7,89)$ & \multirow{2}{*}{0,661} & \multirow{2}{*}{44,91} & \multirow{2}{*}{0,512} \\
\hline & Mais de 2 anos & $12,93(6,81)$ & & & \\
\hline \multirow{2}{*}{ Trabalha } & Sim & $13,02(5,77)$ & \multirow{2}{*}{0,274} & \multirow{2}{*}{85,70} & \multirow{2}{*}{0,785} \\
\hline & Não & $13,41(7,84)$ & & & \\
\hline \multirow{2}{*}{ Tem filho(s) } & Sim & $9,36(5,90)$ & \multirow{2}{*}{2,367} & \multirow{2}{*}{14,28} & \multirow{2}{*}{0,033} \\
\hline & Não & $13,97(7,13)$ & & & \\
\hline \multirow{2}{*}{ Religião } & Sim & $13,96(7,21)$ & \multirow{2}{*}{1,201} & \multirow{2}{*}{76,36} & \multirow{2}{*}{0,233} \\
\hline & Não & $12,16(6,95)$ & & & \\
\hline \multirow{2}{*}{ Religiosidade } & Alta & $14,82(7,73)$ & \multirow{2}{*}{2,09} & \multirow{2}{*}{57,17} & \multirow{2}{*}{0,040} \\
\hline & Baixa & $11,79(6,22)$ & & & \\
\hline
\end{tabular}

Conforme mostra a Tabela 3, numa análise de correlação de Pearson das variáveis de interesse com o escore total de Homofobia Internalizada, foram encontradas correlações positivas significativas com as variáveis Escore de religiosidade $(P=0,009)$, Homofobia externa $(P=$ $0,001)$ e Satisfação Conjugal $(P=0,002)$ e correlações negativas não-significativas com Idade, Renda Individual, Tempo de relacionamento e Tempo que moram juntos.

A partir dos resultados das variáveis significativas na correlação de Pearson e dados demográficos, foi realizada uma regressão linear tendo como variável dependente homofobia internalizada. Como mostra a Tabela 4, o modelo final contou com as variáveis "Sexo", "Escore de religiosidade", "Possui religião", "Tempo de relacionamento", "Ter filho(s)" e "Satisfação Conjugal, que foram estatisticamente significantes como associadas à homofobia internalizada, sendo que tal modelo tem uma variância explicada de $27,6 \%$ ( $\mathrm{R}$ de 0,57 ).

\section{Discussão}

Mesmo diante da relevância do tema homofobia internalizada e religiosidade, a produção acadêmica brasileira na área ainda é incipiente. Sendo assim, este estudo propõe instigar a discussão sobre como esta relação pode se estabelecer. Como já foi dito, estudos de Costa e cols. (2015) mostraram relação entre religiosidade e conservadorismo ético com preconceito contra diversidade sexual. Os dados obtidos nesta pesquisa apontam que altos níveis de religiosidade estiveram presentes em sujeitos que apresentaram altos níveis de homofobia internalizada, corroborando a hipótese do estudo. Tal dado leva a necessidade de se discutir como a religião afeta o autojulgamento do indivíduo homossexual. 
Tabela 3

Correlação de Pearson entre Escalas Utilizadas e Dados Demográficos

\begin{tabular}{|c|c|c|c|c|c|c|c|c|}
\hline & & 2 & 3 & 4 & 5 & 6 & 7 & 8 \\
\hline \multirow{3}{*}{1} & $r$ & 0,010 & 0,164 & $0,269^{* *}$ & $0,238^{*}$ & $0,320^{* *}$ & $-0,018$ & $-0,098$ \\
\hline & $P$ & 0,923 & 0,116 & 0,009 & 0,021 & 0,002 & 0,863 & 0,475 \\
\hline & $N$ & 94 & 93 & 94 & 94 & 92 & 94 & 55 \\
\hline \multirow{3}{*}{2} & $r$ & & 0,154 & $0,326^{* *}$ & 0,037 & $-0,029$ & 0,029 & 0,217 \\
\hline & $P$ & & 0,139 & 0,001 & 0,723 & 0,783 & 0,779 & 0,111 \\
\hline & $N$ & & 93 & 94 & 94 & 92 & 94 & 55 \\
\hline \multirow{3}{*}{3} & $r$ & & & $0,315^{* *}$ & 0,193 & $-0,029$ & 0,036 & 0,019 \\
\hline & $P$ & & & 0,002 & 0,064 & 0,786 & 0,733 & 0,889 \\
\hline & $N$ & & & 93 & 93 & 91 & 93 & 54 \\
\hline \multirow{3}{*}{4} & $r$ & & & & $-0,039$ & $-0,078$ & $-0,165$ & $-0,110$ \\
\hline & $P$ & & & & 0,707 & 0,458 & 0,112 & 0,423 \\
\hline & $N$ & & & & 94 & 92 & 94 & 55 \\
\hline \multirow{3}{*}{5} & $r$ & & & & & $0,432^{* *}$ & $0,518^{* *}$ & $0,326^{*}$ \\
\hline & $P$ & & & & & 0,000 & 0,000 & 0,015 \\
\hline & $N$ & & & & & 92 & 94 & 55 \\
\hline \multirow{3}{*}{6} & $r$ & & & & & & $0,374^{* *}$ & 0,064 \\
\hline & $P$ & & & & & & 0,000 & 0,644 \\
\hline & $N$ & & & & & & 92 & 54 \\
\hline \multirow{3}{*}{7} & $r$ & & & & & & & $0,891^{* *}$ \\
\hline & $P$ & & & & & & & 0,000 \\
\hline & $N$ & & & & & & & 55 \\
\hline
\end{tabular}

Notas. Legenda: 1 - Escore de Religiosidade; 2 - Homofobia Externa; 3 - Satisfação Conjugal; 4 - Homofobia Internalizada; 5 - Idade; 6 - Renda Individual; 7 - Tempo de relacionamento; 8 - Tempo que moram juntos.

$* p>0,05 ; * * p>0,001$.

\section{Tabela 4}

Regressão Linear para Homofobia Internalizada

\begin{tabular}{lcccc}
\hline Modelo: Homofobia Internalizada & Carga & Erro Padrão & Beta & $p$ \\
\hline Sexo & $-4,10$ & 1,41 & $-2,90$ & 0,005 \\
Escore de Religiosidade & 0,34 & 0,097 & 3,50 & 0,001 \\
Possui Religião & $-2,72$ & 1,83 & $-1,48$ & 0,14 \\
Tempo de Relacionamento & $-0,4$ & 0,018 & $-2,26$ & 0,026 \\
Ter filho(s) & $-6,45$ & 2,034 & $-3,17$ & 0,002 \\
Satisfação Conjugal & 0,26 & 0,087 & 3,048 & 0,003 \\
\hline
\end{tabular}


Nos dias atuais, a religião ainda se firma como instância reguladora de valores, difundindo um ideário de certo e/ou errado, que acaba atuando como meio de controle social (Meneses \& Cerqueira-Santos, 2013). Mesmo se tratando de jovens heterossexuais de pastorais evangélicas, ela apresenta significativa influência no comando da iniciação sexual (Verona \& Regnerus, 2014). Igrejas pentecostais agem de forma a diminuir o tempo livre dos jovens, criando grupos de namoro e de aconselhamento, fazendo com que eles dediquem a maior parte da sua rotina ao ambiente religioso. Deste modo, acabam criando um espaço em que o sexo e a sexualidade são encarados como tabu, já que valorizam a virgindade e o sexo pós-casamento, o que pode afetar indiretamente o comportamento sexual e reprodutivo dos indivíduos (Verona \& Regnerus, 2014).

Estudos como os de Pereira e cols. (2011) e Sung (2014) mostram como a religiosidade pode influenciar em direção a um posicionamento negativo com relação à homossexualidade. Silva e cols. (2008) apontam como é dada uma forte ênfase à problematização do "estilo de vida homossexual". A presença de um julgamento moral sobre as práticas homossexuais e referências ao estilo de vida gay são diversas. Na percepção de que o "pecado homossexual" está em desafiar uma ordem de mundo instaurada por Deus, práticas homoafetivas constariam como uma afronta à "determinação divina” (Natividade, 2006).

A mensagem religiosa completa-se na afirmação de que o desejo homossexual é passível de mudança. A homossexualidade é, assim, uma máscara sob a qual jaz uma natureza heterossexual que pode e deve ser revelada, uma inclinação condizente com o sexo biológico. Segundo as pastorais evangélicas que se propõem a curar o indivíduo gay de seu pecado, o que está em foco para que haja esta mudança é a busca do exercício da vontade (Natividade, 2006), que exige afinco do então indivíduo homossexual a exercitar seu processo de "cura". Este discurso, segundo Miskolci (2009), "expressa as expectativas, as demandas e as obrigações sociais que derivam do pressuposto da heterossexualidade como natural e, portanto, fundamento da socie- dade", podendo ser entendida como "um conjunto de prescrições que fundamenta processos sociais de regulação e controle, até mesmo [para] aqueles que se relacionam com pessoas do sexo oposto" (p. 156). Mesmo os católicos, que costumam considerar a possibilidade de a homossexualidade constituir uma expressão da natureza de alguns indivíduos, enfatizam a necessidade de incentivar a prática do celibato e cultivo do amor de Deus (Natividade \& de Oliveira, 2009).

Desta forma, fica perceptível a validade da existência da relação entre religiosidade e homofobia internalizada encontrada neste estudo, pois, em resumo, a religião condena o comportamento homossexual, que é encarado como algo errado, influenciando diretamente no juízo de valor dos indivíduos. Assim, como dita Hernández (2013), o jovem gay religioso, através do processo de dissociação cognitiva e de blindagem da própria identidade, reproduz tal discurso, o que acabará afetando seu bem-estar, difundindo ideais preconceituosos que serão direcionados, inclusive, a ele mesmo.

É importante ressaltar que algumas religiões encaram de forma distinta a orientação sexual dos indivíduos. Como afirma (Silva \& cols., 2008), os líderes religiosos afro-brasileiros demonstram-se mais abertos se comparados com as autoridades pentecostais. Jovens umbandistas apresentaram maior abertura e respeito à diversidade sexual, enquanto jovens evangélicos pentecostais se posicionaram tal como preconizam as leis ditadas por suas autoridades religiosas, ou seja, defendem que Deus "não aprova" a homossexualidade. Esta é concebida como "pecado" e a própria Igreja forneceria subsídios para que mulheres e homens sejam "libertados" dela, caso queiram se aproximar das leis divinas e de Deus.

Satisfação conjugal é um termo que busca resumir e acatar as problemáticas que envolvem um relacionamento (Scorsolini-Comin \& dos Santos, 2010). São grandes os avanços e conquistas do público LGB neste aspecto, como o direito de ser reconhecido como casal, concedido em 2011 (Santos, Scorsolini-Comin, \& dos Santos, 2013) e a resolução do CNJ de 2013 que permite a celebração do casamento civil ou de 
conversão da união estável em casamento civil para casais do mesmo sexo (Resolução $\mathrm{N}^{\circ} 175$, de 14 de maio de 2013). Apesar do avanço jurídico, a aceitação social para a existência plena do casal homoafetivo ainda é baixa. Tal fato pode acarretar dificuldade na vivência amorosa, pois indivíduos que possuem homofobia internalizada teriam mais pudor e receio de demonstração pública, optando por um relacionamento discreto, "entre quatro paredes". Deste modo, a presença de homofobia internalizada entre o casal homossexual afetaria a satisfação conjugal como um todo, já que sempre haveria uma barreira impedindo o exercício da sua liberdade afetiva.

\section{Conclusão}

A promoção de valores e práticas de respeito à diversidade de orientações sexuais e identidades de gênero seguramente é um mecanismo importante para que diferentes grupos sociais passem a ter uma visão de mundo menos heteronormativa, o que amplia as possibilidades de formação de uma opinião pública mais favorável, inclusive, à aprovação de leis que assegurem cidadania plena à população LGBT (Mello, Brito, \& Maroja, 2012). Os resultados deste estudo evidenciam que a demanda de combate contra a homofobia vai além do melhoramento de aspectos sociais e da vida pública. Os elementos deste embate devem, também, visar aspectos individuais, entre eles a religiosidade e a satisfação conjugal, as duas variáveis que mais se destacaram neste estudo como significativas no entendimento da homofobia internalizada.

Algumas limitações foram encontradas no decorrer deste estudo. A amostra foi composta por indivíduos de maioria jovem e com pouco tempo de relacionamento, o que pode gerar um viés no resultado encontrado. Ainda do ponto de vista metodológico, o fato de os participantes integrarem outro estudo maior sobre conjugalidade pode ter gerado respostas semelhantes entre os pares de convivência. Do ponto de vista conceitual, a falta de literatura que explore estas duas variáveis dificulta parâmetros de comparação para os dados encontrados nesse estudo.
É pertinente, portanto, neste momento, acenar para a necessidade de estudos que ampliem a discussão acerca destes e de outros aspectos que podem estar relacionados à homofobia internalizada e que podem interferir no bem-estar do indivíduo homossexual. Sem retirar a importância de discutir aspectos da vida pública e dos direitos à plena cidadania dos indivíduos LGBT, o olhar para como esta constante luta por direitos e aprovação social deve ser voltado para entender a forma como estas instâncias afetam e modificam seu entendimento sobre si e seu bem-estar subjetivo.

\section{Referências}

Barrientos, J., \& Cárdenas, M. (2013). Homofobia y calidad de vida de gay y lesbianas: una mirada psicosocial. Psykhe, 22(1), 3-14. Recuperado em http://www.scielo.cl/scielo.php?pid=S0718$-22282013000100001 \&$ script $=$ sci_arttext

Borrillo, D. (2000). L'Homophobie. Paris: Presses Universitaires de France.

Cerqueira-Santos, E., Koller, S. H., \& Pereira, T. (2004). Religião Saúde e Cura: Um estudo entre neopentencostais. Psicologia Ciência e Profissão, 24(3), 82-91.

Cerqueira-Santos, E., Koller, S. H., \& Wilcox, B. (2008). Condom use, contraceptive methods, and religiosity among youths of low socioeconomic level. The Spanish Journal of Psychology. 11(1), 94-102.

Costa, A. B., \& Nardi, H. C. (2015). Homofobia e preconceito contra diversidade sexual: Debate conceitual. 2015. Temas em Psicologia 23(3), 715-726. doi:10.9788/TP2015.3-15

Costa, A. B., Peroni, R. O., Camargo, E. S., Pasley, A., \& Nardi, H. C. (2015). Prejudice toward gender and sexual diversity in a Brazilian public university: Prevalence, awareness, and the effects os education. Sexuality Research and Social Policy. doi:10.1007/s13178- 015-0191-z

Coutinho, R. Z., \& Miranda-Ribeiro, P. (2014). Religião, religiosidade e iniciação sexual na adolescência e juventude: Lições de uma revisão bibliográfica sistemática de mais de meio século de pesquisas. Revista Brasileira Estudos de População, 31(2), 333- 365. 
Durkheim, E. (2003). Elementary forms of the religious life. São Paulo, SP: Martins Fontes. (Original work published in 1915)

Eribon, D. (1999). Réflexions sur la question gay. Paris: Fayard.

Eribon, D., \& Haboury, F. (2003). Dictionnaire des cultures gay et lesbiennes. Paris: Editions Larousse.

Falcke, D. (2003). Àguas passadas não movem moinhos?: As experiências na família de origem como preditoras da qualidade do relacionamento conjugal (Tese de doutorado, Pontifícia Universidade Católica do Rio Grande do Sul, Porto Alegre, RS, Brasil).

Freires, L. A. (2015). Atitudes frente à homoparentalidade: Uma explicação a partir de variáveis explícitas e implícitas (Tese de doutorado em Psicologia Social, Universidade Federal da Paraíba, João Pessoa, PB, Brasil). Recuperado em http:// tede.biblioteca.ufpb.br/bitstream/tede/7521/2/ arquivototal.pdf

Herek, G. M. (2000). The psychology of sexual prejudice. Current Directions in Psychological Science, 9, 19-22.

Herek, G. M. (2004). Beyond "homophobia": Thinking about sexual stigma and prejudice in the twenty-first century. Sexuality Research and Social Policy, 1, 6-24.

Herek, G. M., \& Mclemore, K. A. (2013). Sexual prejudice. Annual Review of Psychology, 60, 309-333.

Hernández, J. (2013). Filhas de famílias homoparentais: Processos, confrontos e pluralidades (Dissertação de mestrado, Universidade Estadual do Rio de Janeiro, RJ, Brasil).

Mello, L. A., Avelar, R. B., \& Brito, W. (2014). Políticas públicas de segurança para a população LGBT no Brasil. Estudos Feministas, 22(1), 416. Recuperado em http://www.scielo.br/pdf/ ref/v22n1/16.pdf

Mello, L., Brito, W., \& Maroja, D. (2012). Políticas públicas para a população LGBT no Brasil: Notas sobre alcances e possibilidades. Cadernos Pagu, 39, 403-429.

Meneses A. F. S., \& Cerqueira-Santos, E. (2013). Sexo e Religião: Um estudo entre jovens evangélicos sobre o sexo antes do casamento. Clínica \& Cultura, 2(1), 82-94. Recuperado em http:// www.seer.ufs.br/index.php/clinicaecultura/article/view/1541
Miskolci, R. A (2009). Teoria Queer e a Sociologia: O desafio de uma analítica da normalização. Sociologias (Porto Alegre), 11(21), 150-182. Recuperado em http://www.scielo.br/pdf/soc/ n21/08.pdf

Natividade, M. (2006). Homossexualidade, gênero e cura em perspectivas pastorais evangélicas. Revista brasileira de Ciências Sociais, 21(61), 115-132.

Natividade, M. T., \& de Oliveira, L. (2009). Sexualidades ameaçadoras: Religião e homofobia(s) em discursos evangélicos conservadores. Sexualidad, Salud y Sociedad: Revista Latinoamericana, 2, 121-161.

Pereira, C. R., Torres, A. R. R., Pereira, A. S. P., \& Falcão, L. (2011). Preconceito contra homossexuais e representações sociais da homossexualidade em seminaristas católicos e evangélicos. Psicologia: Teoria e Pesquisa, 27, 73-82.

Pereira, H., \& Leal, I. (2005). Medindo a homofobia internalizada: A validação de um instrumento. Análise Psicológica, 3(XXIII), 315-318. Recuperado em http://www.scielo.mec.pt/pdf/aps/ v23n3/v23n3a10.pdf

Resolução No 175, de 14 de maio de 2013. (2013). Dispõe sobre a habilitação, celebração de casamento civil, ou de conversão de união estável em casamento, entre pessoas de mesmo sexo. Brasília, DF: Conselho Nacional de Justiça. Recuperado em http://www.cnj.jus.br/ images/imprensa/resolução_n_175.pdf

Rodrigues, P. (2010). Homofobia internalizada e suicidalidade em jovens LGB e não LBG. Les Online, 2(2), Recuperado em http://www.lespt. org/lesonline/index.php?journal=lo\&page $=$ artic le\&op=viewFile\&path $\% 5 \mathrm{~B} \% 5 \mathrm{D}=35 \&$ path $\% 5 \mathrm{~B}$ $\% 5 \mathrm{D}=34$

Santos, Y. G. de S., Scorsolini-Comin, F., \& dos Santos M. A. (2013). Homoparentalidade masculina: Revisando a produção científica. Psicologia: Reflexão e Crítica, 26(3), 572-582.

Scorsolini-Comin, F., \& dos Santos, M. A. (2010). Satisfação conjugal: Revisão integrativa da literatura científica nacional. Psicologia: Teoria e Pesquisa, 26(3), 525-531.

Silva, C. G. da, Santos, O. A., Licciardi, D. C., \& Paiva, V. (2008). Religiosidade, juventude e sexualidade: entre a autonomia e a rigidez. Psicologia em Estudo, 13(4), 683-692. 
Sung, J. M. (2014). Prosperidade sim, família homossexual, não! A nova classe média evangélica. Psicologia USP, 26(1), 43-51.

Teixeira-Filho, F. S., \& Marreto, C. A. R. (2008). Apontamentos sobre o atentar contra a própria vida, homofobia e adolescências. Revista de Psicologia da UNESP (Assis, SP), 7(1), 133-51. Recuperado em http://www2new.assis.unesp.br/ index.php/revista/article/viewArticle/115/129
Verona, A. P. A., \& Regnerus, M. (2014). Pentecostalism and premarital sexual initiation in Brazil. Revista Brasileira Estudos de População, 31(1), 99-115.

Recebido: 30/12/2015

$1^{a}$ revisão: 19/04/2016

Aceite final: 21/04/2016 